\title{
Secador de Sementes para o Pequeno Agricultor: Uma Proposta com Estimação Dinâmica das Variáveis de Secagem
}

\author{
Tarso R. Avila ${ }^{1}$, Nicácia P. Machado ${ }^{1}$, Adenauer C. Yamin ${ }^{1}$, Marcelo Lemos Rossi $^{2}$ \\ ${ }^{1}$ Universidade Católica de Pelotas (UCPel). Pelotas - RS - Brazil \\ ${ }^{2}$ Universidade Federal de Pelotas (UFPel) Pelotas - RS - Brasil \\ \{tarso.avila, nicacia.machado, adenauer.yamin\}esou.ucpel.edu.br, \\ marcelo.rossiaufpel.edu.br
}

\begin{abstract}
Small-scale seed production is common practice by small producers who resist commercial imposition for food production with narrow genetic variability, considered a threat to the planet's agrobiodiversity. In this context, there are the so-called seed guardians, who adopt practices of peasant origin for the production of foods of great genetic variability. According to studies in the field of seed production technology, drying before storage is considered one of the primary steps. However, there are regions where the weather conditions are not favorable for drying seeds, as well as it is usual to lack technologies in this sense for small producer. Therefore, verifying this need, the general objective of this work is the design of an equipment for the effective drying of small seed lots, taking into account the culture of the seed involved and the local weather conditions. The results achieved were promising, pointing to the continuity of the research.
\end{abstract}

Resumo. A produção de sementes em pequena escala é prática comum por pequenos produtores que resistem à imposição comercial para produção de alimentos com variabilidade genética estreita, considerada ameaça para agrobiodiversidade do planeta. Nesse contexto, existem os chamados guardiões de sementes, que adotam práticas de origem camponesa para a produção de alimentos de grande variabilidade genética. Segundo estudos na área de tecnologia de produção de sementes, a secagem antes do armazenamento é considerada uma das etapas primordiais. Contudo, existem regiões nas quais as condições meteorológicas não são favoráveis para secagem das sementes, bem como é usual faltar tecnologias neste sentido para o pequeno produtor. Portanto, verificando essa necessidade, o objetivo geral deste trabalho é a concepção de um equipamento para a eficaz secagem artificial de pequenos lotes de sementes, levando em consideração a cultura da semente envolvida e as condições meteorológicas locais. Os resultados atingidos se mostraram promissores, apontando para a continuidade da pesquisa.

\section{Introdução}

Os autores [Pelwing et al. 2008], ao analisarem a revolução verde que causou a perda da diversidade e variabilidade das plantas cultivadas transformando os agroecossistemas em monocultivos de variedade genética estreita, destacam os agricultores e agricultoras que 
mantêm viva, a partir da conservação, uma diversidade de plantas, as quais são denominadas plantas tradicionais, antigas, caseiras, landraces ou crioulas. Esse tipo de conservação é realizado por comunidades agrícolas tradicionais e/ou familiares, as quais atuam como mantenedoras da diversidade biológica natural, com práticas agrícolas de baixo impacto.

Para realizar a conservação da diversidade de plantas é necessário pensar na sua relação com as sementes. A manutenção dessas sementes é uma tarefa primorosa, que necessita métodos e cuidados. Para [Bevilaqua et al. 2013] "A manutenção da qualidade das sementes envolve a adoção de tecnologias que evitam que essas percam a qualidade durante a fase de entressafra [Bevilaqua et al. 2013]. Uma dessas etapas é a secagem das sementes, que deve ser executada antes do armazenamento. Conforme [Camacho et al. 2004], o processo de secagem de sementes é uma das etapas principais para a produção de sementes de alta qualidade. A secagem reduz o teor de água para níveis adequados possibilitando o armazenamento e mantendo a sua qualidade fisiológica.

As tecnologias de secagem de sementes amplamente difundidas para os grandes produtores que trabalham com sementes de pequena variedade genética, não chegam ao pequeno produtor. Dessa forma, o pequeno produtor que, por sua vez, trabalha com sementes de grande variabilidade genética, muitas vezes utiliza técnicas inadequadas para a secagem.

Na produção de sementes, principalmente nos estados do Sul do Brasil, a secagem artificial é um dos métodos amplamente utilizados por empresas de sementes, devido às vantagens que o método apresenta. Porém, é uma operação sensível que pode apresentar danos irreversíveis para as sementes se não forem tomados os devidos cuidados, importantes para preservar a sua qualidade fisiológica [de CARVALHO 1994, Almeida et al. 1999].

Observando as constatações supracitadas, este trabalho tem como objetivo central a concepção de uma proposta para atuar na secagem de sementes de pequenos lotes, levando em consideração condições meteorológicas e a ciência ligada à tecnologia de produção de sementes, visando alta qualidade e vigor. Para tanto, algumas técnicas foram desenvolvidas para estimar as variáveis de processo do equipamento protótipo, como processamento de sinais, instrumentação, eletrônica de potência, controle e estimação.

O artigo está organizado como segue. A Seção 2 trata de sistematização de conceitos em secagem de sementes. Na Seção 3 é apresentada a metodologia seguida no trabalho. Na Seção 4 os resultados alcançados são apresentados e discutidos. Por fim, na Seção 5 são apresentadas as conclusões e sugestões de trabalhos futuros.

\section{Sistematização de Conceitos em Secagem de Sementes}

A partir das tecnologias de produção de sementes, sabe-se que o momento ideal para a colheita da semente deve ser o mais próximo da sua maturidade fisiológica quando os teores de água são superiores a 30\% [Villela and da Silva 1992]; [Peske and Barros 1997]; [Miranda et al. 1999].

Para [Camacho et al. 2004], o intervalo de tempo entre o término da colheita das sementes e o início do processo de secagem deve ser o menor possível, pois é nesta fase do processo de produção que as sementes com maior índice de umidade apresentam grandes atividades respiratórias e o consumo antecipado de suas reservas provoca o desgaste 
fisiológico, ocasionando baixos índices de germinação e vigor no futuro.

As metodologias de secagem de sementes utilizadas pelos pequenos agricultores variam. Uma delas é a secagem natural que utiliza energias disponíveis na natureza, como a eólica e a solar. Com condições ambientais favoráveis é o método mais indicado para a secagem de sementes, pois o processo de secagem ocorre lentamente. Porém, esse tipo de secagem é extremamente dependente das condições ambientais. Já a secagem artificial modifica as propriedades físicas do ar ambiente. Uma das formas é aumentando a sua temperatura e fluxo de ar [Bevilaqua et al. 2013].

A maioria das sementes são colhidas quando atingem a maturidade fisiológica e depois são secas para o armazenamento. As sementes de feijão, por exemplo, quando atingem a maturidade fisiológica, apresentam teores de umidade variando entre 30 e $44 \%$ [Carvalho and Nakagawa 2000]. Nessa faixa de umidade as sementes de feijão devem ser colhidas e secas para armazenagem. E assim como para a maioria das sementes, as sementes de feijão têm umidade ótima para armazenamento na faixa de 11 a $13 \%$ de umidade [de Andrade et al. 2006].

Quando a umidade das sementes está em equilíbrio com o meio que as rodeiam é chamada de umidade de equilíbrio ou equilíbrio higroscópico. A umidade de equilíbrio de uma amostra de sementes é em função da umidade relativa do ar, da temperatura e das propriedades das sementes [Berbert et al. 2008]. Conhecendo a temperatura e umidade relativa do ambiente de secagem, é possível calcular o teor de umidade em que as sementes tendem a ficar depois de determinado tempo sob as condições de secagem. Essa tendência é devido ao equilíbrio higroscópico.

Dentre os diversos modelos utilizados para o cálculo de umidade de equilíbrio de sementes e grãos, escolhemos o modelo proposto por Henderson, descrito pela equação 1, no qual a umidade de equilíbrio é explicitada. Esta equação utiliza a equação de adsorção de Gibbs. Esse modelo é um dos mais utilizados na estimação do teor de umidade de equilíbrio de grãos e sementes [Almeida et al. 1999].

$$
U e=\frac{\ln (1-U R)^{\frac{1}{N}}}{-C \times T}
$$

Onde:

Ue: Umidade Relativa, decimal;

$T$ : Temperatura do ambiente em Celsius;

$C$ e $N$ : Constantes que dependem do material, conforme Tabela 1;

$U e$ : Umidade ou teor de água de equilíbrio, decimal (b.s.).

Tabela 1. Constantes para alguns tipos de sementes.

\begin{tabular}{|c||c|c|}
\hline Produto & $C$ & $N$ \\
\hline \hline Milho & $1,98 \times 10^{-5}$ & 1,9 \\
\hline Sorgo & $6,12 \times 10^{-6}$ & 2,31 \\
\hline Feijão Preto & 6,0197 & 2,6143 \\
\hline
\end{tabular}

Conforme as propriedades higroscópicas das sementes, o processo de secagem ocorre por causa dos gradientes de pressões de vapor de água entre as sementes e o ar 
de secagem que tendem a se igualar. Uma das formas mais difundidas de aumentar a diferença de pressões de vapor de água da superfície da semente e do ar de secagem é com o aquecimento deste último. Como consequência do aquecimento do ar, a umidade relativa diminui e o ar adquire maior capacidade de secagem [Nunes 2016].

A umidade relativa (UR) do ar pode ser definida como a relação entre a pressão parcial de vapor de água presente no ar e a pressão de vapor de saturação na mesma temperatura, equação 2. Normalmente, a umidade é expressa em porcentagem [Berbert et al. 2008].

$$
U R=\frac{P v}{P v s(T)} \times 100
$$

Onde:

$U R$ : Umidade Relativa;

$\operatorname{Pvs}(T)$ : Pressão de vapor de saturação;

$P v$ : Pressão parcial de vapor.

\section{Metodologia}

Na parte mecânica do secador existem duas câmaras, uma chamada de Plenum e outra de secagem, um trocador de calor (aquecedor elétrico), um eletro-ventilador, um par de sondas. As sondas estão dispostas da seguinte forma: uma sonda que mensura temperatura e umidade dentro da câmara de secagem (sensores internos); e a outra sonda mensurando temperatura e umidade na parte externa do equipamento (sensores externos). Essa concepção estrutural pode ser vista na Figura 1.

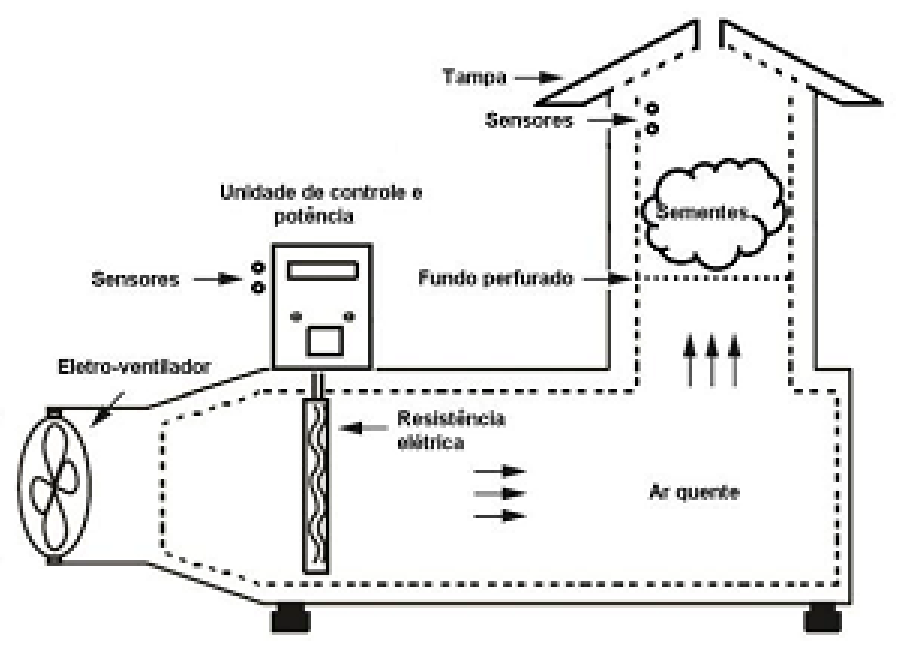

Figura 1. Secador de Sementes e Componentes. Modificada de[Silva et al. 2014].

O dispositivo utilizado para mensurar temperatura e umidade é o SHT31DIS, do fabricante Sensirion, que possui em seu chip um sensor de temperatura e umidade. Estes dispositivos possuem comunicação digital do tipo $\mathrm{I}^{2} \mathrm{C}$ e possuem alta precisão e exatidão.

O equipamento possui uma interface homem-máquina, contendo três botões e um display, que serve para escolher o tipo da semente que deverá ser seca, iniciar e parar o processo de secagem e visualizar a temperatura interna e setpoint de temperatura estimado 
pelo sistema. Neste sistema, existe um microcontrolador e um computador, processando um algoritmo distribuído. Uma visão macro do sistema enfatizando o microcontrolador e seus periféricos, bem como barramentos de interligação, pode ser visto na Figura 2.

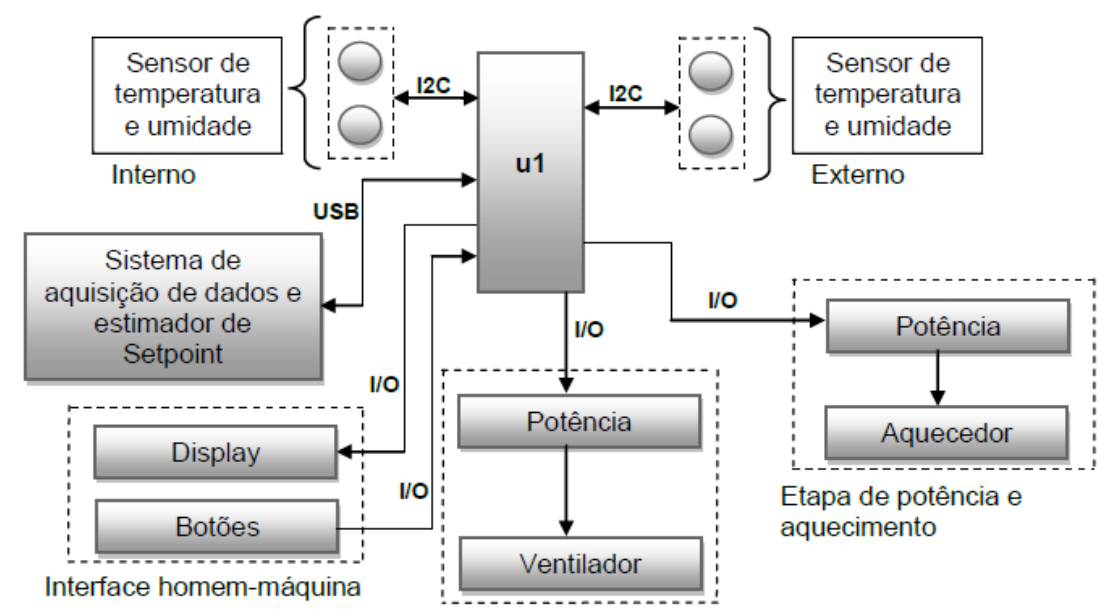

Figura 2. Estrutura geral do sistema eletrônico. Fonte o autor.

Por meio da potência elétrica fornecida ao elemento aquecedor o ar é aquecido. Para a escolha do elemento aquecedor, alguns aspectos foram levados em consideração, como a capacidade de aquecimento do ar ambiente que entra no equipamento a partir de uma temperatura de $8^{\circ} \mathrm{C}$ até $40^{\circ} \mathrm{C}$, mensurados dentro da câmara de secagem. A temperatura de $40^{\circ} \mathrm{C}$ é a máxima temperatura a qual as sementes podem ser submetidas. Neste range de temperatura, infinitos valores de temperatura são possíveis por meio do correto acionamento da resistência e das condições meteorológicas do ambiente.

Aliando os princípios de solução desejados e procurando uma máquina (ventilador) viável comercialmente, se chegou à escolha do ventilador Tubo-axial, que faz conjunto com o aquecedor elétrico e carcaça no qual o motor também é fixado. Por facilidades, utilizou-se o controle de aquecimento, comumente chamado de $O N / O F F$, o qual apresenta uma zona de histerese, proporcionado por uma tolerância de temperatura. $\mathrm{Na}$ etapa de acionamento da resistência, utilizou-se um circuito de potência flexível contendo um Tiristor e um isolador galvânico para seu comando. O controle do ventilador é implementado via sistema digital e para seu acionamento foi utilizado um transistor de efeito de campo (FET - Field Effect Transistor) e uma fonte auxiliar chaveada de 24 volts.

O microcontrolador, ao ser energizado, mostra telas de apresentação e de instrução para o usuário, que deseja secar as sementes. Na primeira tela solicita para o usuário estabelecer uma conexão do equipamento com o software Matlab. Para se estabelecer a conexão, o dispositivo USB aparece como uma porta serial para o computador, pois foi emulado pelo dispositivo USB. Ao executar o script no software Matlab, o mesmo cria um objeto de conexão serial e abre a porta. Nesse momento, o microcontrolador aguarda instruções e fica dependente do software Matlab.

Para o equipamento iniciar a secagem, o mesmo precisa saber se tem sementes dentro da câmara de secagem e o tipo de semente. O tipo de semente é necessário para parametrizar o sistema estimador implementado, lembrando que cada semente tem seus coeficientes (Tabela 1). Após informado o tipo de semente ao equipamento, se inicia a 
secagem. Nesse momento, é mensurado as grandezas de temperatura e umidade relativa interna (dentro da câmara de secagem) e temperatura e umidade relativa externa (fora da câmara de secagem). Esses valores são armazenados a cada 1 segundo pelo sistema, em variáveis no computador (software Matlab). O processamento que o sistema faz para obter o valor de referência (setpoint) de temperatura pode ser visto na Figura 3.E o processamento que o sistema distribuído faz para estimar qual seria a umidade relativa do ar após um acréscimo de temperatura no ar ambiente, é baseado na Equação 2.

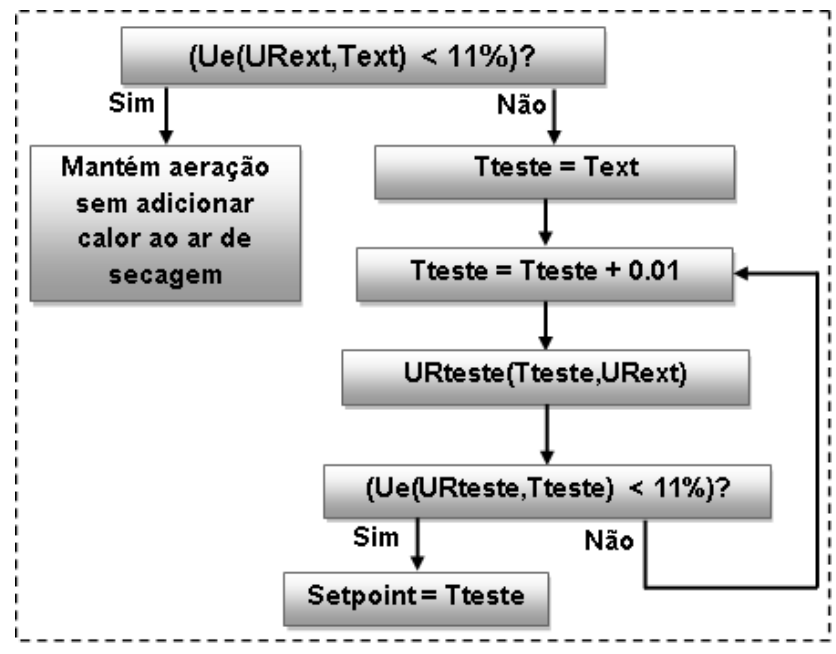

Figura 3. Algoritmo para estimativa da umidade relativa. Fonte o autor.

Sendo assim, utilizando o algoritmo apresentado na Figura 3 para a secagem com sementes de feijão, o equipamento atua da seguinte forma:

1. No primeiro instante, o mesmo mensura as grandezas externas e internas (umidade relativa e temperatura) e aciona o ventilador (aeração) e formata todas as grandezas para serem compatíveis com o sistema estimador de umidade e de equilíbrio higroscópico;

2. Parametriza o modelo estimador, de acordo com o tipo de semente escolhido no início da secagem;

3. Calcula o equilíbrio higroscópico para as condições de umidade relativa e temperatura externa (fora da câmara de secagem);

4. Se o cálculo retorna $11 \%$ ou abaixo de umidade, ou seja, naquelas condições ambientais a semente pode ser seca, o sistema só mantém a aeração ligada. Caso o cálculo retorne valores acima de $11 \%$ é adicionado o valor da leitura de temperatura externa a uma variável de acumulação e é feito a primeira iteração. Se adiciona $0,01{ }^{\circ} \mathrm{C}$ ao valor da variável acumulação e se estima a umidade relativa do ar, após o acréscimo de $0,01^{\circ} \mathrm{C}$, e se faz o cálculo de equilíbrio higroscópico para o par de temperatura e umidade relativa estimada. Se o cálculo retornar valores acima de $11 \%$, o algoritmo faz novamente a iteração. O sistema faz isso iterativamente até encontrar o primeiro par de temperatura e umidade estimada que atendam as necessidades para a semente entrar em equilíbrio higroscópico com o ar. Quando encontrado o valor de temperatura que fará a semente atingir $11 \%$ de umidade, utiliza-se esse valor de temperatura como setpoint para o sistema de controle de temperatura, que fará com que o ar de secagem contenha a temperatura desejada e, consequentemente, a umidade estimada. 
A aquisição de dados é feita a cada 1 segundo, o sistema de controle de temperatura também é atualizado neste intervalo e o estimador, processado a cada 1 minuto.

\section{Resultados}

A parte mecânica e eletroeletrônica ficou igual ao projeto teórico, previsto nas etapas de projeto (Figura 4).

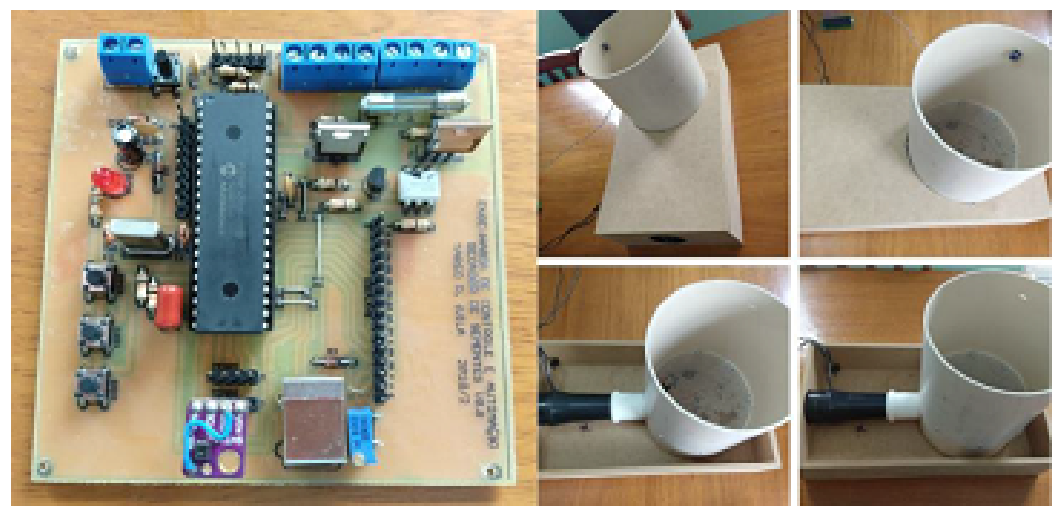

Figura 4. Imagens protótipo. Fonte o autor.

Com o equipamento construído, foi possível avaliar seu desempenho, por meio da aquisição feita pelo sistema. O ensaio de secagem foi feito no dia 7/12/2018, começando a secagem $09 \mathrm{~h} 40 \mathrm{~min}$ até às $10 \mathrm{~h} 40 \mathrm{~min}$, com sementes de feijão com teor de água inicial desconhecido. O tipo de semente informado para o sistema foi "feijão", portanto, os cálculos de estimativa foram processados para este tipo de cultura. Nas Figuras 5 e 6 é possível observar as variáveis externas temperatura e umidade relativa.

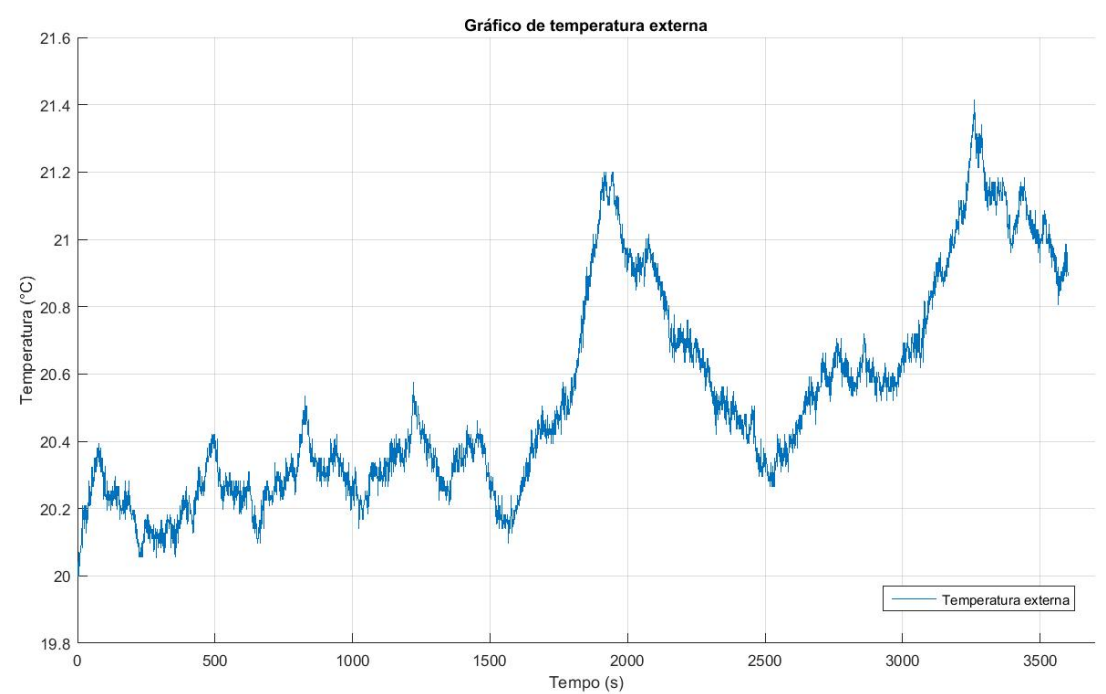

Figura 5. Gráfico de temperatura externa, ensaio de secagem. Fonte o autor.

Nas Figuras 7 e 8 é possível observar as variáveis dentro da câmara de secagem. Usa-se esses valores de temperatura e umidade dentro da câmara de secagem na equação 1, ou seja, com as verdadeiras condições impostas sobre as sementes, para verificar a 


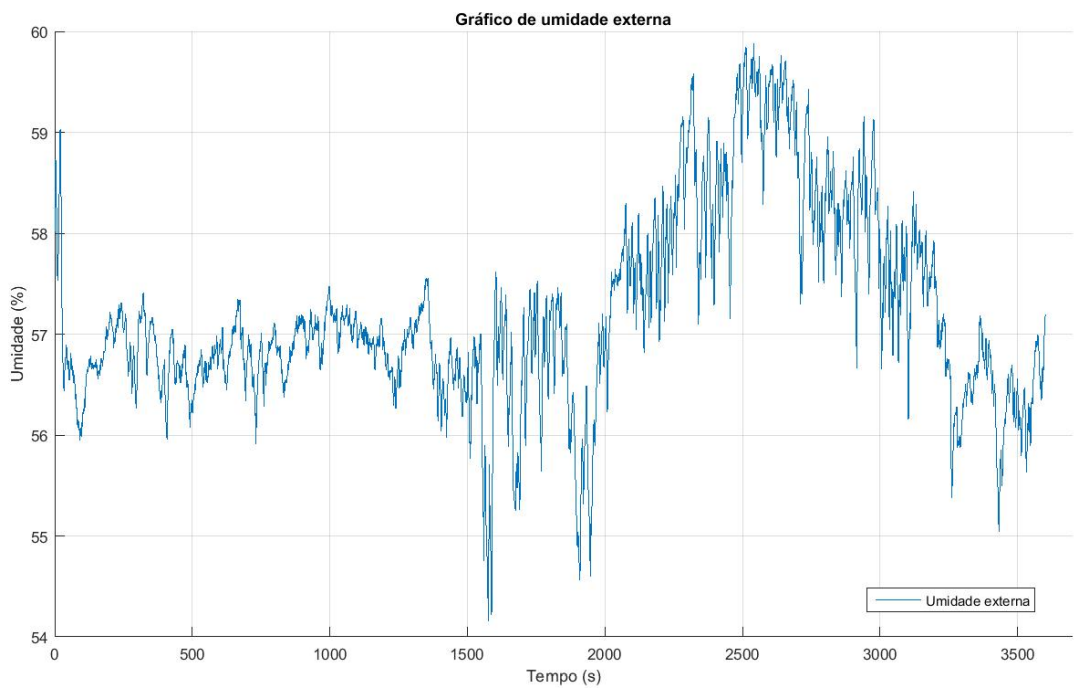

Figura 6. Gráfico de umidade externa, ensaio de secagem. Fonte o autor.

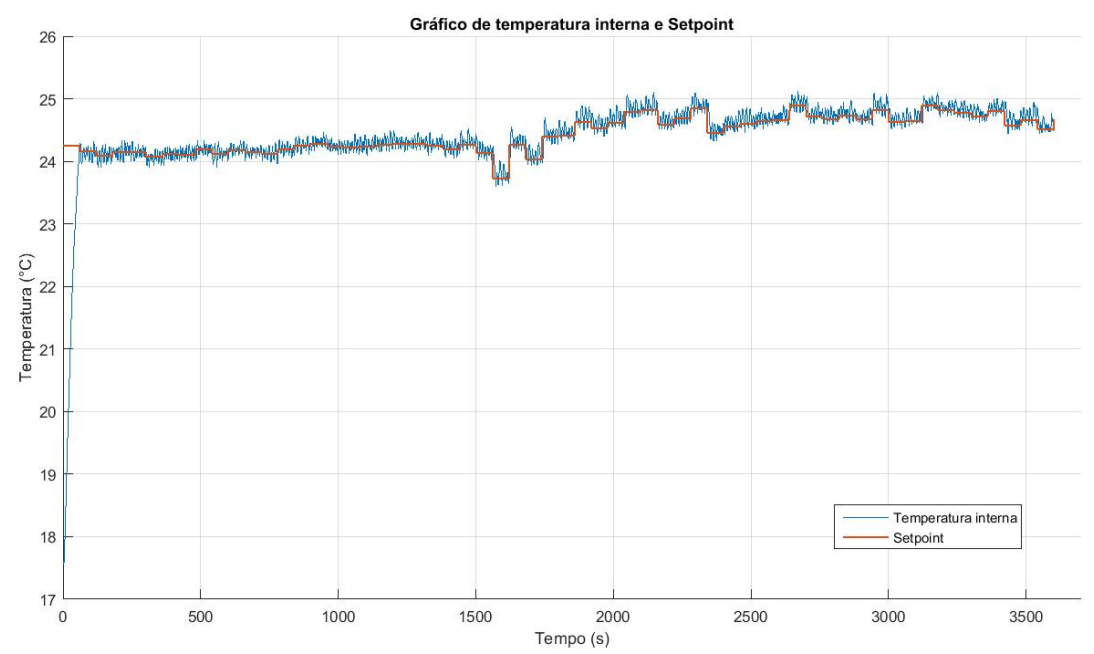

Figura 7. Gráfico de temperatura interna e setpoint, ensaio de secagem. Fonte o autor.

umidade de equilíbrio. Se observa que após 1000 segundos de secagem já é possível obter valores de tendência de umidade das sementes abaixo de 12\% (figura 9).

Com os resultados de umidade e temperatura interna obtidos durante a secagem do feijão preto é possível observar que as sementes estão em um ambiente controlado, com condições possíveis para chegarem ao teor de água desejado, de acordo com as Equações do modelo de Henderson. Os valores abaixo de 12\% após 1000 segundos de secagem indicam o valor de umidade em que as sementes tendem a ter ao final da secagem.

\section{Conclusões}

Tendo por base os resultados obtidos, entende-se que as premissas previstas para o projeto foram contempladas de forma satisfatória, pois obteve-se um protótipo capaz de atender as funcionalidades previstas quando da sua concepção inicial, as quais foram corroboradas pelos vários resultados referentes ao desempenho do protótipo sob diferentes condições 


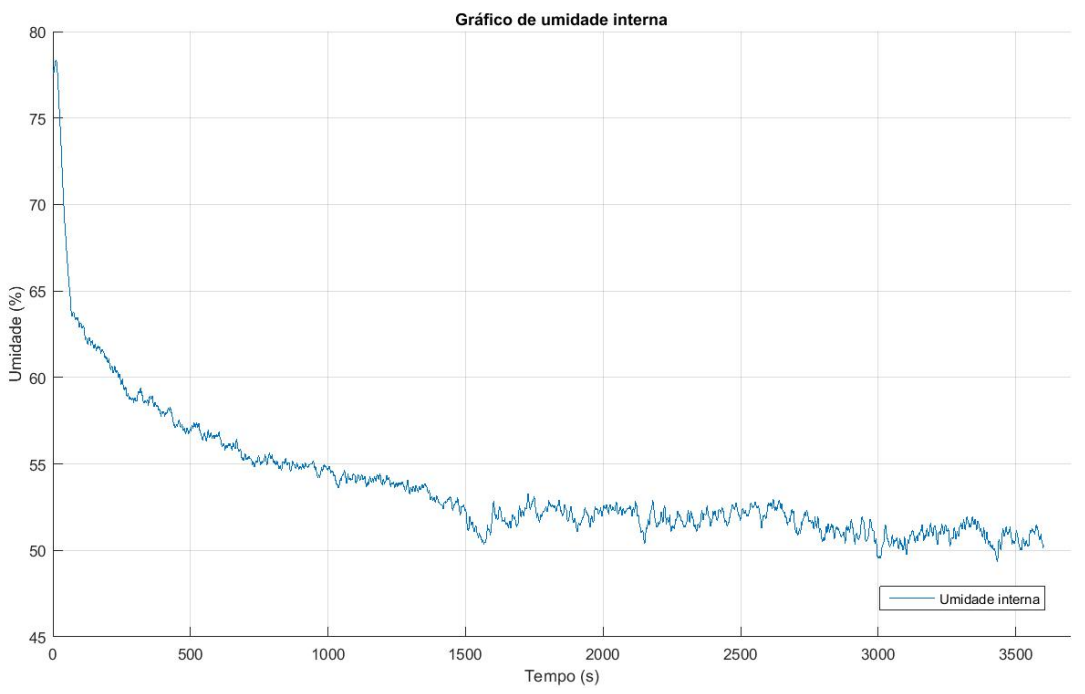

Figura 8. Gráfico de umidade interna, ensaio de secagem. Fonte o autor.

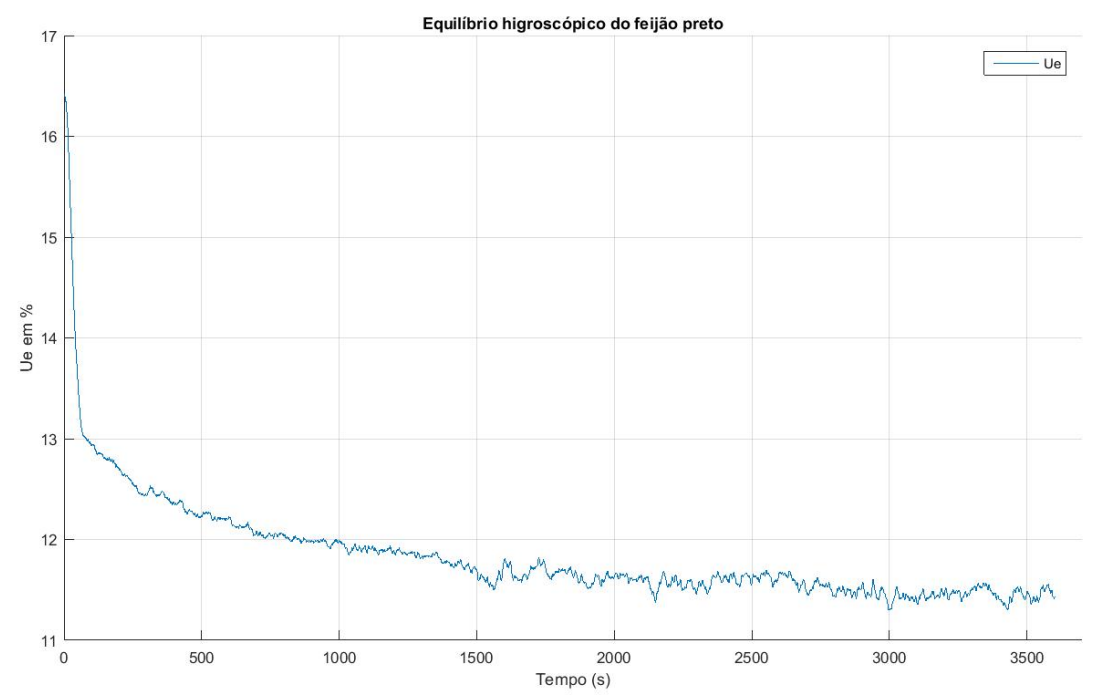

Figura 9. Gráfico estimado de de equilíbrio higroscópico da semente a partir de temperatura e umidade dentro da câmara de secagem, ensaio de secagem. Fonte o autor.

operacionais, ao longo do tempo de avaliação.

Dentre as diversas alternativas para continuidade da pesquisa referente ao trabalho desenvolvido, destacam-se o emprego de técnicas de Aprendizado de Máquina para aferição do teor de umidade durante o processo de secagem.

\section{Referências}

Almeida, F. d. A. C., Fonseca, K. S., and Gouveia, J. P. G. d. (1999). Secagem natural de gergelim e determinação da umidade de equilíbrio. Revista Brasileira de Engenharia Agrícola e Ambiental, 3(3):343-348.

Berbert, P. A., Silva, J., Rufato, S., and Afonso, A. (2008). Indicadores da qualidade dos grãos. Secagem e armazenagem de produtos agrícolas. 
Bevilaqua, G., Antunes, I., Eberhardt, P., Eichholz, C., and Grehs, R. (2013). Indicações técnicas para produção de sementes de feijão para a agricultura familiar. Embrapa Clima Temperado-Circular Técnica (INFOTECA-E).

Camacho, D. G., Barros, A. C. S. A., Peske, S. T., and de Menezes, N. L. (2004). A secagem de sementes. Ciência Rural, 34(2):603-608.

Carvalho, N. and Nakagawa, J. (2000). Sementes: ciência, tecnologia e produção. 4: ed. jaboticabal: Funep.

de Andrade, E. T., Correa, P. C., Teixeira, L. P., Pereira, R. G., and de Freitas Calomeni, J. (2006). Cinética de secagem e qualidade de sementes de feijão. Engevista, 8(2).

de CARVALHO, N. (1994). A secagem de sementes. Jabuticabal : FUNEP.

Miranda, L. C., Silva, W. R. D., and Cavariani, C. (1999). Secagem de sementes de soja em silo com distribuição radial do fluxo de ar: I. monitoramento físico. Pesquisa Agropecuária Brasileira, 34(11):2097-2108.

Nunes, J. L. d. S. (2016). Tecnologia de sementes: Secagem, beneficiamento e armazenagem. https://www . agrolink.com.br/sementes/tecnologia-sementes/

secagem--beneficiamento-e-armazenagem_361343.html. (Acessado em 23/06/2020).

Pelwing, A. B., Frank, L. B., and Barros, I. I. (2008). Sementes crioulas: o estado da arte no rio grande do sul. Revista de Economia e Sociologia Rural, 46(2):391-420.

Peske, S. and Barros, A. (1997). Produção de sementes de arroz. Produção de arroz irrigado. Pelotas: UFPel, pages 351-412.

Silva, L. M. d. M., Sousa, F. C. d., Sousa, E. P. d., Cavalcanti Mata, M. E. R. M., and Duarte, M. E. M. (2014). Modelos de predição da cinética de secagem dos grãos de guandu. Brazilian Journal of Food Technology, 17(4):310-318.

Villela, F. and da Silva, W. (1992). Curvas de secagem de sementes de milho utilizando o método intermitente. Scientia agrícola, 49(SPE):145-153. 